\title{
LA ESTRUCTURA DEL PROCESO DE FORMACION DE GOBIERNO. EL CASO ESPAÑOL EN EL MARCO DEL DERECHO COMPARADO
}

\author{
POR \\ LUIS AGUIAR \\ Profesor Adjunto de Derecho Político \\ Universidad Complutense
}

Sin duda alguna, uno de los fenómenos característicos de la vida política contemporánea es la importancia cobrada en el marco de las instituciones por ese órgano prácticamente ignorado por la teoría constitucional clásica hasta que Michoud escribiera en 1889 su conocida obra Des actes gouvernement y que conocemos en la actualidad con la expresión de «gobierno».

Sin embargo, en la actualidad, el gobierno aparece en los textos constitucionales como un órgano colegiado, jurídicamente homogéneo y titular de unas funciones parcamente definidas, pero extensamente virtualizadas, que lo han convertido en el centro de acción política más relevante del Estado contemporáneo. Los procedimientos de formación de gobierno son de este modo piedra angular en alguna de las clasificaciones de los sistemas políticos contemporáneos ${ }^{1}$, y la puesta en marcha de tales procesos constituye en la actualidad uno de los períodos de mayor intensidad política. Pero además, el análisis de dicho tema es quizá igualmente uno de los puntos en que más claramente se pone de manifiesto las insuficiencias de la teoría jurídica clásica, tanto por la inflexión que en relación a dicho tema se ha producido en los sistemas constitucionales contemporáneos, como por el elevado número de variables y elementos no formales que confluyen en su delimitación.

Sin embargo, no es posible olvidar la importancia que el marco jurídico desempeña en tales ocasiones. De un lado, por el papel legitimador que desarrolla dicha normativa, pues, como dijera Blondel ${ }^{2}$, «en tanto ese problema (se refiere a la regulación jurídica del nombramiento de gobierno) no se resuelva felizmente y prevalezca la incertidumbre, los adversarios del gobierno se resistirán probablemente a aceptar las decisiones de éste y buscarán procedimientos ilegales para derrocarlo». De otro lado, porque dichas normas contienen una importante distribución de parcelas de poder, que es preciso mati-

\footnotetext{
1 Así, la distinción clásica entre sistemas presidenciales, parlamentarios y de asamblea descansa en gran medida en este punto.

2 J. Blondel, Introducción al estudio comparativo de los gobiernos, Madrid, 1972, pág. 372.
}

Revista del Departamento de Derecho Politico

Núm. 6. Primavera 1980 
zar. En el presente trabajo no es mi intención agotar las múltiples facetas e implicaciones que el tema encierra ${ }^{3}$, sino tan sólo ordenar en base a la teoría constitucional y el Derecho comparado los principales problemas que plantea el proceso de nombramiento de gobierno, a partir de las transformaciones estructurales sufridas por el Estado contemporáneo, y con ello aclarar algunas de las cuestiones que suscita la puesta en práctica del artículo 99 de nuestra vigente Constitución.

\section{EVOLUCION HISTORICA DE LAS FORMAS DE NOMBRAMIENTO DE GOBIERNO}

$\mathrm{La}$ institución gubernamental, desconocida hasta épocas recientes a nivel constitucional, en la medida en que es básicamente una creación empírica del régimen parlamentario como punto de conexión de las prerrogativas regias y la voluntad popular expresada en el Parlamento, ha sufrido históricamente un movimiento pendular en sus vías de nombramiento y legitimación. Baste recordar su incorporación al constitucionalismo español del siglo XIX, que, aunque no precisamente modélico, dado su carácter marcadamente artificial, puede ser considerado un fiel reflejo de la evolución del constitucionalismo liberal; ausencia de la institución gubernamental en la Constitución de Cádiz; aparición de hecho en el trienio liberal; virtualidad en la práctica constitucional del Estatuto real, y tímida constitucionalización como apéndice del poder ejecutivo detentado por el rey en la Constitución de 1837, bajo la genérica expresión de «los ministros», posición inalterable que mantedrá a nivel constitucional hasta el Título VI de la Constitución de 1931, en que aparece ya como un órgano diferenciado ${ }^{4}$. El gobierno pasa así de ser un ejecutor de las perrogativas regias que permite el control parlamentario de aquéllas, a un órgano comisionado de las Cámaras, pasando por un punto de equilibrio que es la Monarquía orleanista.

Evidentemente dicha evolución no podía por menos de dejarse sentir en el proceso de nombramiento del gobierno, que pasa de ser designado libremente por el monarca ${ }^{5}$, a mecanismos más o menos explícitos de participación del órgano representativo, e incluso popular, al menos en su cabeza visible, como empezaba a suceder en las colonias británicas convertidas en los Estados Unidos.

De este modo, en el constitucionalismo liberal clásico, que encuentra sus mejores exponentes en los textos o enmiendas constitucionales de finales del siglo pasado (así, las leyes constitucionales de la III República francesa, la Constitución suiza del 74 o los textos constitucionales de las monarquías nór-

\footnotetext{
${ }^{3}$ Baste comprobar la abundante literatura sobre el tema y que se recoge sumariamente al final del presente trabajo.

- Véase J. T. Villarroya, La formación de gobierno durante la II República, en «Revista de Estudios Políticos», n. 204 (1975).

${ }^{5}$ «Cuando se trata de nombramientos (de ministros se entiende), el monarca decide por sí; constituye uno de sus derechos inalienables», dirá B. Constant en 1815 en Principios de política, cap. II.
} 
dicas, entre otros), la designación del gobierno aparece cuasi monopolizada por la representación popular, bien sea de modo explícito, a través de la moción de investiduda, bien sea de modo tácito, mediante la designación por otro órgano (el Jefe del Estado como poder neutral en Benjamín Constant), pero supeditado a la posibilidad de revocación por el órgano parlamentario.

Sin embargo, dicho proceso de nombramiento de gobierno no obedece tan sólo a razones históricas y coyunturales, como pudiera parecer tras una lectura anecdótica de la historia constitucional británica, sino que obedece a razones estructurales más profundas de organización del poder en el Estado liberal, como ha mostrado el profesor García de Enterría ${ }^{6}$.

De un lado, la ley, expresión de la voluntad general, y, por tanto, mandato racional en cuanto elaborada por unos representantes libremente elegidos, que actúan en virtud de esa ficción tan racionalista y tan liberal como es el mandato representativo, y que llevan a cabo la formación de la voluntad parlamentaria a través de un procedimiento igualmente racional: el diálogo, el debate parlamentario. De otro lado, el gobierno, que aparece, según decía Duguit en su clásico Tratado de Derecho Constitucional, como un comisionado del Parlamento, como «un agente colocado bajo la autoridad y control de los órganos de representación» ${ }^{7}$.

Sin embargo, y con palabras del profesor Rubio Llorente, «dicho esquema, que como esquema teórico sigue siendo plenamente vigente, poco o nada tiene que ver con lo que realmente pasa en nuestro tiempo» ${ }^{8}$, pues desde el último cuarto de siglo pasado y primeros años de éste, el gobierno va a ir cobrando una paulatina autonomía en la práctica constitucional, y no sólo, como dijera Kaustky, porque el Parlamento constituyera un lugar peligroso para las clases dominantes, que se acantonan en el gobierno ante el riesgo de que el Parlamento sea conquistado por las clases dominadas a través del sufragio ${ }^{9}$, sino que obedece también aquí a causas más estrictamente estructurales.

La manifestación de dicho desfase entre el sistema y el marco constitucional será la consabida inestabilidad gubernamental, fruto de las desavenencias entre un gobierno que el sistema precisa autónomo y activo y un Parlamento investido constitucionalmente de amplias facultades de control; y no pienso que la mera restricción constitucional de dichas facultades, como de hecho se intentará tras la segunda guerra mundial, sea la única solución, sino que estamos en presencia de las primeras manifestaciones de la crisis de la teoría jurídica clásica.

En cuanto a las causas de dicho decalage, parece obvio advertir de su enorme variedad, pero continuando la línea argumental precedentemente seguida para el Estado liberal clásico, creo que se pueden referir a un punto central: el cambio de las relaciones sociedad-Estado y el consiguiente cambio de los procesos de legitimación. 1972

- E. García de Enterría, Revolución francesa y Administración contemporánea, Madrid,

${ }_{7}^{7}$ L. Duguit, Traité de Droit constitutionnel, vol. II, París, 1928, pág. 243.

${ }^{8}$ F. Rubio Llorente, Relación entre el gobierno y las Cortes, en Constitución, economía y regiones, vol. II, Madrid, 1978, pág. 60 .

${ }^{\circ} \mathrm{K}$. Kaustky, La Révolution sociale, París, 1912. 
Las primeras quiebras estructurales del Estado liberal se pueden situar en las crisis económicas de los años setenta y ochenta del pasado siglo, que llevan al abandono del sistema de libre cambio y la aparición de las primeras intervenciones económicas del Estado ${ }^{10}$. Sin embargo, será la primera guerra mundial la que hace ya necesaria la intervención masiva del Estado en la producción y distribución, intervencionismo que se agudizará por la grave crisis económica posbélica. No me detendré en los hitos y rasgos de dicho proceso; constatemos tan sólo el punto de llegada con palabras del profesor García Pelayo: «El Estado y la sociedad no son ya dos sistemas autónomos, autorregulados, unidos por un número limitado de variables, sino dos sistemas fuertemente interrelacionados entre sí a través de relaciones complejas, con factores reguladores que están fuera de los respectivos sistemas y con un conjunto de subsistemas interseccionados» ${ }^{11}$.

El Estado no puede limitarse entonces a crear las condiciones jurídicas ambientales de un mercado supuestamente autorregulado, sino que ha de asumir una actitud activa, patentizada en constantes medidas. $\mathrm{El}$ postulado de la igualdad formal y el sufragio como exclusivos principios de legitimación han de ceder así paso a la racionalidad instrumental o técnica y a la eficacia, para las que el debate parlamentario de los representantes libremente elegidos no resulta útil. La función de la ley cambia así por completo de sentido, en el Estado contemporáneo, como ha estudiado Franz Neumann, pero también la posición y designación del Gobierno se ve sustancialmente alterada, que cobra ahora una especial autonomía; con palabras de Jürgen Habermas, «la participación del ciudadano en los procesos de formación de la voluntad política, es decir, la democracia material, llevaría a la conciencia la contradicción entre una producción administrativamente socializada y un modo de apropiación y de empleo de la plusvalía que sigue siendo privado. Para que esa contradicción no sea tematizada, el sistema administrativo debe alcanzar suficiente autonomía respecto de la formación de la voluntad legítimamente» ${ }^{12}$. Ahora bien, si el gobierno cobra en el Estado contemporáneo un elevado margen de autonomía, a la par que se convierte en el punto central de los órganos constitucionales, el proceso de nombramiento de gobierno se ve nuevamente alterado, aunque tan sólo sea porque su limitación para ejercer importantes parcelas del poder político no se funda primaria y exclusivamente en ser el ejecutor de las prerrogativas regias o el comisionado del Parlamento, sino en

10 J. Habermas, Concepto de participación política, en Capital monopolista e involución autoritaria, Barcelona, 1973, pág. 26. Dicho intervencionismo estatal como fenómeno político se había manifestado con anterioridad, aunque como ha puesto de manifiesto $P$. Vilar (Crecimiento y desarrollo, Barcelona, 1976, págs. 403 y 404), tiene un carácter subsidiario. $\mathrm{La}$ novedad de la década setenta-ochenta lo constituye el que dicho intervencionismo tiene su reflejo en el marco institucional de los poderes públicos, con la aparición de figuras como el decreto-ley.

${ }^{11}$ M. García Pelayo, Las transformaciones del Estado contemporáneo, Madrid, 1977, pág. 25.

${ }_{12}$ J. Habermas, Problemas de legitimación en el capitalismo tardio, Buenos Aires, 1975, pág. 53. Para un análisis general de la transformación de las relaciones entre los poderes, véase por todos C. de Cabo, División y predominio de poderes, en El control parlamentario del gobierno en las..., Barcelona, 1978. 
su propia eficacia y capacidad de ejercer la dirección e impulsión del sistema político ${ }^{13}$. Pero es que además, el marco institucional se ha visto profundamente alterado, pues el juego político básico no se desenvuelve ya entre un gobierno que ejecuta y un Parlamento que traza las líneas generales de orientación política y controla ulteriormente cómo se han ejecutado aquéllas, sino que se desenvuelve entre una mayoría actuante y una oposición en espectativa.

Sería vano pensar que la trayectoria de dicha evolución puede ser interrumpida e incluso cambiada de sentido por medios constitucionales, como se ha pensado por algunos sectores durante nuestro reciente proceso constituyente. Evidentemente, la técnica jurídico-constitucional ha forjado institutos y mecanismos que han propiciado la autonomización de las estructuras gubernamentales en favor de una nueva legitimidad, pero han sido sobre todo las transformaciones de los partidos políticos y la profesionalización de la clase política la vía por excelencia por la que se ha materializado dicha autonomía ( $\mathrm{y}$ en cierta medida hegemonía) del gobierno frente a las Cámaras, en un proceso que no ha cesado de incrementarse desde comienzos del presente siglo; así, en $1925 \mathrm{H}$. Laski apuntaba que es «axiomático en este aspecto que el poder ejecutivo se vincula a los líderes del partido que asume el poder», y de modo aún más explícito y taxativo, C. Schmitt dirá: «El partido mayoritario forma el gobierno legal y maneja todos los medios del poder estatal para la ejecución de la ley...; quien tiene la mayoría, hace las leyes vigentes y pone en vigor las leyes elaboradas por el mismo» ${ }^{14}$.

No es de extrañar, por tanto, la importancia que con frecuencia han tomado el estudio de los partidos y las relaciones entre ellos como vía de análisis del proceso de nombramiento de gobierno. De una parte, la teoría de los juegos, creada originariamente para analizar problemas económicos, se ha intentado aplicar a la formación de coaliciones, como si se tratase de un juego en que los jugadores son los grupos parlamentarios y el premio la participación en el gobierno ${ }^{15}$. De otro lado, con un enfoque más predominante-

${ }^{13}$ Un desarrollo de esta cuestión puede verse en J. Porres Azkona, La decisión sobre facultades excepcionales, CEC (mecanografiado), 1979.

${ }_{14} \mathrm{H}$. Laski, El Estado moderno, vol. II, Barcelona, 1932, pág. 80; C. Schmitt, Legalidad y legitimidad, Madrid, 1971, pág. 48.

${ }_{15}$ Las líneas de investigación en que se ha orientado la teoría de coaliciones son básicamente dos, aunque siempre referidas al sistema de partidos. De una parte, aplicando la teoría de los juegos, creada originariamente para analizar problemas económicos, se ha intentado aplicar a la formación de coaliciones como si se tratase de un juego en que los jugadores son los grupos parlamentarios y el premio la participación en el gobierno. Von Neumann y Morgesten, a quienes corresponden los primeros estudios, en este sentido, dirán que una coalición no incluirá partido alguno que no fuera necesario para vencer, pues en un juego de suma cero los vencedores no desean repartir el botín entre más partidos de los necesarios. Sobre esta base, Leiserson incorporará el principio de negociación, esto es, que las coaliciones se forman en base a integrar el menor número de partidos posible, pues el proceso de negociación es más fácil cuando en él participan menor número de jugadores. Finalmente, en esta dirección, Riker, a quien corresponde la teoría más elaborada, añadirá que sólo se formarán coaliciones mínimas, en cuanto que la coalición que reúne menor número de escaños es la capaz de ofrecer a sus miembros una mayor gatantía. Sin embargo, esta dirección parte de una quiebra de principio, como ha puesto de manifiesto J. Attali, esto es, se acepta como evidente que cualquier actor del juego político 
mente jurídico, Von Beyme, en su clásico estudio sobre el régimen parlamentario, analiza los principios y criterios que se siguen en la determinación del partido en torno al cual se lleva a cabo la formación de gobierno y, en su caso, la coalición ${ }^{16}$.

Sin embargo, el enfoque jurídico no carece de interés, y no sólo por las razones precedentemente apuntadas respecto a la importancia de los cauces jurídicos en los procesos de nombramiento de gobierno, sino que además, desde una perspectiva más amplia, la nueva configuración del Estado y del gobierno ha encontrado su reflejo en la regulación constitucional de dicho tema, suscitando nuevas cuestiones y replanteando las tradicionales bajo la nueva perspectiva (principalmente las relaciones mayoría-oposición como tensión institucional básica del Estado contemporáneo).

En este sentido, y a efectos de encuadrar el problema, es preciso advertir que las transformaciones estructurales del Estado contemporáneo han afectado al tratamiento constitucional del proceso de nombramiento de gobierno, que en estos momentos se ve traspasado por dos pares de principios contrapuestos, en torno a cuya adecuada satisfacción giran los diferentes modelos: de un lado el principio de representatividad, al que aparece como contrapunto el principio de eficacia, y de otro, el principio de temporalidad, confrontado al principio de estabilidad.

En efecto, es rasgo característico de los Estados contemporáneos el proclamar, aunque sea formalmente, un alto nivel de participación popular en la designación de los gobernantes, incluso en modelos políticos que se encuen-

puede formar coalición con cualquier otro para lograr la participación en el gobierno. Resulta así preciso introducir otras variables rectificadoras, en especial la ideológica, tarea que ha desarrollado la segunda dirección de la teoría de la formación de coaliciones representada principalmente por Axelrod, Sartori, De Swan y aplicada al régimen parlamentario por Colliard. Véase López Guerra y Varela en Las coaliciones de gobierno en la II República española, en El control parlamentario del gobierno en las..., Barcelona, 1978.

${ }_{16}$ Von Beyme reconduce a cinco principios los criterios seguidos habitualmente en la determinación del partido en torno al cual se lleva a cabo la formación de gobierno: $e l$ principio de mayoría, esto es, el partido mayoritario a nivel parlamentario forma gobierno sin mayores objeciones; el principio de pluralidad, que equivaldría a la formación de gobierno por o en torno a la minoría más numerosa (se trata de un principio básico de la vida parlamentaria, y cuyo no tespeto causaría graves problemas a Alcalá Zamora en las Cortes de 1933-35 por su reiterada negativa a encargar la formación de gobierno a Gil Robles, líder del grupo parlamentario más importante); el principio de culpabilidad, es decir, el encargado de formar gobierno saldría de las filas del partido responsable de la crisis gubernamental (el origen y mayor virtualidad de este principio corresponde al régimen parlamentario británico del pasado siglo, donde se estimó una transgresión de las normas al uso, que el líder de un partido en la oposición, y que hubiera provocado la caída de un gobierno, intentara zafarse de la responsabilidad de formar gobierno, y una cierta constitucionalización de este principio de culpabilidad lo constituye la moción de censura constructiva); el principio plebiscitario supone que se encarga de formar gobierno el partido que ha registrado el mayor avance a nivel electoral, en base a que en esa coyuntura concreta es el que goza de mayor respaldo popular, y finalmente, Von Beyme utiliza un concepto residual y escasamente explicativo, al que denominará principio de gravitación, y que podría resumirse brevemente con sus propias palabras: «Existen otros gobiernos en los que la determinación del partido pivot no responde a ninguno de los principios precedentes, sino a su peculiar posición en el espectro político, que le permite aglutinar tras de sí una coalición suficiente para formar gobierno» (Die parlamentarischen..., págs. 499-521). 
tran alejados del concepto político de representación, participación popular que ha de alcanzar obviamente a la estructura gubernamental, núcleo central en el que se residencia el poder político en los Estados contemporáneos. Sin embargo, dicho principio de representatividad se ve confrontado con la exigencia de eficacia, igualmente inexcusable de los ejecutivos contemporáneos, y en la que el profesor Sánchez Agesta ha visto la principal explicación de su autonomía. Manifestación del principio de representatividad son todas aquellas formas y variedades de participación popular en el proceso de nombramiento de gobierno, de que me ocuparé a continuación, frente a las que aparecen una igualmente amplia gama de mecanismos constitucionales destinados a conferir coherencia y eficacia al equipo gubernamental; así por ejemplo, entre otras, el principio de responsabilidad colectiva, frecuente en el constitucionalismo contemporáneo. Del segundo par de principios contrapuestos existe, asimismo, un amplio espectro, pues si la estabilidad gubernamental es una de las preocupaciones básicas de los textos constitucionales, en especial, a partir de la segunda guerra mundial, que se manifiesta incluso en los supuestos de cambio de gobierno, proveyendo medidas para evitar el vacío de poder, la temporalidad en el cargo es también uno de los elementos esenciales, al menos del modelo liberal, temporalidad que, si en algunas ocasiones se concreta en un período fijo de vida para el equipo gubernamental, el llamado por Blondel turno automático, característico pero no exclusivo del régimen presidencial, en otras ocasiones queda supeditado constitucionalmente al control de otro órgano, normalmente la Cámara Baja.

A partir de tales consideraciones, ¿cuáles son las variedades institucionales del constitucionalismo contemporáneo? Obviamente la regulación de los textos constitucionales es muy diversa, debido al gran número de elementos en juego, los cuales se articulan material y procesalmente en múltiples variedades. Sin embargo, siguiendo a Duverger en una tipología acuñada en $1961{ }^{17}$, y tomando tan sólo los lineamientos generales, tales variedades se pueden reconducir a dos grupos: de un lado, la designación popular de la cabeza visible del ejecutivo, calificada por Duverger, con expresión no muy acertada, como «democracia directa», y de otro, la designación del gobierno con mediación expresa o tácita del órgano parlamentario, y a la que el autor francés denomina «democracia mediatizada».

Entre los primeros, la designación por vía popular, pocas son las observaciones que suscita a los efectos aquí buscados, y éstas se pueden reconducir a lo que tradicionalmente se conoce como régimen presidencial.

Por tanto, más interesante resulta la designación con mediación parlamentaria, o democracia mediatizada, entre las que cabe encuadrar a la Constitución española, y que plantea amplias cuestiones teóricas y políticas. Así, si la definición misma del sistema institucional descansa en gran medida en este dato ${ }^{18}$, la estructuración constitucional del proceso condiciona el peso de los diferentes órganos estatales que en él participan.

${ }_{17}^{17}$ M. Duverger, La VI Republique et le régime presidentiel, París, 1961.

18 Así, la distinción entre Monarquía constitucional y Monarquía parlamentaria se apoya, entre otras cuestiones, en este dato; véase I. Otto, Sobre la Monarquía, en La izquierda y la Constitución, Barcelona, 1978. 
En efecto, como he indicado, la mediación parlamentaria puede ser bien tácita, cuando la designación se lleva a cabo por otro órgano, que ha de contar con la correlación de fuerzas parlamentarias ante el riesgo de una moción de censura para el gobierno recién nombrado, bien expresa, cuando se exige de un modo u otro una votación de investidura. Evidentemente, el parlamentarismo negativo (aplicable también a la $\mathrm{V}$ República francesa) da un mayor contenido al papel del Jefe del Estado, pero igualmente el momento en que se produce la votación parlamentaria de investidura (antes o después del nombramiento por el Jefe del Estado) tiene importantes repercusiones en la configuración de los papeles políticos del Jefe del Estado y del Parlamento. Piénsese, por ejemplo, en la diferente posición y papel desempeñado por la Jefatura del Estado en Bélgica, Italia, Portugal o la II República española, de un lado, y de otro, en la República Federal Alemana, Irlanda o España en la actualidad. La estructura jurídica del proceso de nombramiento de gobierno, lejos de ser irrelevante en el plano político, constituye un elemento de primer interés para comprender el significado político de los diferentes órganos constitucionales del Estado contemporáneo.

\section{EL NOMBRAMIENTO DE GOBIERNO EN LA CONSTITUCION ESPAÑOLA}

Limitando el análisis jurídico a la estructura del proceso de nombramiento de gobierno al caso español, el primer problema lo constituye la elaboración de un modelo que dé cabida a los diferentes elementos que participan en el mismo y que explique satisfactoriamente las fases que lo integran. En el plano político y en base a los regímenes parlamentarios contemporáneos, J. Colliard estructura la totalidad del proceso en tres fases diferenciadas, que abarcan desde la selección previa de candidatos hasta la asignación de carteras ministeriales, pasando por un momento central que es la elección de la fórmula gubernamental y designación del primer ministro ${ }^{19}$. Sin embargo, dicho esquema, aunque válido en principio (y será el que aquí se siga), no deja de resultar controvertido en el plano jurídico. Concretamente la doctrina italiana, preocupada por la inclusión (o no) de la confianza parlamentaria en el procedimiento de nombramiento de gobierno, ha polemizado respecto a la consideración del proceso institucional del nombramiento de gobierno, bien como un único procedimiénto jurídico, o bien como integrado en realidad por dos procedimientos autónomos: uno, el nombramiento de presidente de gobierno, y otro, la asignación de las restantes carteras ${ }^{20}$. Entre nosotros, M. Satrústegui ha sostenido la consideración de todo el proceso como un solo procedimiento jurídico en función de la unidad de resultado la formación de gobierno ${ }^{21}$. Sin embargo, aunque sin demasiada relevancia práctica en el caso español, los argumentos alli empleados no resultan plenamente convincentes, pues la Constitución española separa nítidamente ambos mo-

19 J. C. Colliard, Les régimes parlamentaires contemporains, París, 1978.

${ }^{20}$ Por todos, A. Romano, La formazione del Governo, Padua, 1979.

${ }^{21}$ M. Satrústegui, Ante la formación del próximo gobierno, en El País, 1979. 
mentos en dos preceptos distintos, e incluso en el artículo: 62, al enumerar las funciones del rey, son objeto de consideración separada uno, y otro acto. De otro lado, el hecho de que la toma de posesión sea conjunta (dato en el que Satrústegui hace especial énfasis), supone tan sólo una común asunción de funciones por parte del gobierno y su presidente ${ }^{22}$, pero el procedimiento de configuración de la voluntad estatal para el nombramiento de presidente de gobierno y de los ministros se encuentra culminado con anterioridad, y prueba de ello es la formalización y publicación separada de tales actos (el pasado año, el nombramiento de Addolfo Suárez se llevó a cabo mediante decreto de 31 de marzo, $B O E, 79$, y el de los ministros, mediante decreto de 5 de abril, $B O E, 83$ ).

Así, pues, parece que, en el sistema constitucional español, el proceso de nombramiento de gobierno puede ser analizado tanto política, siguiendo a Colliard, como jurídicamente, en base a las tres fases precedentemente mencionadas: la selección previa de candidatos (de carácter político previo), el procedimiento de nombramiento de primer ministro y el procedimiento de asignación de las restantes carteras ministeriales. Veámoslo separadamente.

\section{A) La selección de candidatos}

La selección de candidatos, estando escasamente formalizada a nivel jurídico, para el Derecho constitucional aparece como un fenómeno previo al margen de su consideración. Dejaré tan sólo constancia de que la selección de candidatos por el rey u otros criterios análogos son residuo histórico, y que en la actualidad dicha función ha pasado a ser monopolizada casi exclusivamente por los partidos políticos que han hecho de ella una de sus principales misiones.

Los modelos a través de los cuales los partidos llevan a cabo la selección de candidatos podrían resumirse a nivel enunciativo como más importantes, y siguiendo a Schawarzemberg ${ }^{23}$, los siguientes:

a) La selección por un órgano estatutario del partido, de carácter amplio y excepcional, cuyo reclutamiento se realiza a través de elecciones abiertas.

b) En segundo lugar, la elección por un órgano ordinario del partido, representativo de sus bases, al menos teóricamente. Normalmente, el Congreso del partido, que designa su candidato a primer ministro o ratifica al que desempeña el cargo (nombramiento que puede recaer en el cargo más relevante dentro del partido - lo más frecuente- o puede igualmente corresponder en determinadas circunstancias a otras personalidades del mismo; así, en determinados períodos del PCUS, en la actualidad en los principales partidos de la R. F. A., o habitualmente en la UDR francesa y en la Democracia Cristiana italiana), modelo que es igualmente el formalmente seguido por los partidos parlamentarios del espectro político español.

${ }^{22}$ Incluso, apurando el argumento, se podría decir que la Constitución habilita para una parcial asunción de funciones al presidente de gobierno nombrado, con anterioridad a la toma de posesión, en cuanto le encomienda la formulación de propuestas de ministros.

${ }^{23}$ R. Schwarzenberg, Politique comparée, vol. II, París, 1973 págs. 315 y sigs. 
c) Puede; en tercer lugar, corresponder a la dirección del partido o a un círculo restringido de aquél (bien sea como fórmula excepcional de sustitución del Congreso del partido, como sucedió en el Partido Socialdemócrata alemán, tras el affaire Guillaume, o bien como procedimiento ordinario, como sucedía en el Partido Conservador británico hasta la reforma estatutaria de 1965).

d) Finalmente, y quizá sea la fórmula más interesante desde el punto de vista teórico, la selección del candidato a premier se lleva a cabo por el grupo parlamentario del partido, siendo en la actualidad los Partidos laborista y conservador británicos los más cualificados exponentes.

\section{B) El nombramiento del presidente de gobierno}

Mayores problemas suscitan las otras dos fases del proceso, donde se sustancia la composición definitiva del gobierno, problemas que se ven agravados en relación al caso español por dos circunstancias de apariencia contradictoria; de un lado, la extremada minuciosidad con que se encuentra regulado dicho tema en la Constitución española (basta releer los artículos que se ocupan de la celebración de consultas previas por el rey o las causas que provocan el cese del gobierno); sin embargo, y aunque pueda parecer paradójico dicha minuciosidad, no excluye, como prueba el Derecho comparado, que aparezcan en el futuro usos y prácticas constitucionales, concretando facultades y poderes que hoy parecen discrecionales o de contenido ambiguo ${ }^{24}, \mathrm{y}$ que la corta vigencia del texto constitucional las hace hoy imposibles.

No obstante, y siguiendo el tenor del texto constitucional y la experiencia del Derecho comparado, es posible establecer inicialmente unas líneas generales de regulación de dicho tema, que podrían resumirse en los siguientes puntos: el hecho desencadenante del proceso institucional de nombramiento de gobierno lo constituye básicamente la crisis del gobierno anterior; dicho proceso institucional, según ha quedado dicho, consta de dos procedimientos jurídicos diferenciados; el procedimento de nombramiento de presidente de gobierno puede revestir dos formas: ordinaria y extraordinaria ${ }^{25}$, culminando en todo caso con el nombramiento del nuevo presidente por el rey; el procedimiento de nombramiento de los ministros se reduce a la propuesta por el presidente y nombramiento por el rey; finalmente, unos y otros nombramientos confluyen en la toma de posesión conjunta, que paralelamente lleva aparejada la pérdida de funciones del gobierno anterior. Veamos, por tanto, a partir de tales ideas básicas, los principales problemas que se suscitan.

En primer término, el proceso de nombramiento de presidente, al igual que cualquier otro procedimiento jurídico, arranca de la facultad concedida

${ }^{24}$ Es sintomático en este punto que dos de los autores que más monográficamente han estudiado el tema, Waleffe y Romano, comienzan sus respectivos trabajos con una amplia descripción sobre la validez de la costumbre como fuente del Derecho constitucional.

${ }^{25}$ L. Sánchez Agesta, El sistema político de la Constitución española de 1978, Madrid, 1980 , pág. 229. 
a alguno de los órganos estatales para, mediante un acto o declaración de voluntad, poner en funcionamiento a los restantes órganos partícipes en el proceso de nombramiento. Dicha facultad tiene su fundamento en una situación de hecho que aparece como insatisfactoria y que a través del susodicho proceso se viene a subsanar: la existencia de un gobierno cesante o en funciones.

Sin embargo, la Constitución española en su minuciosidad incurre en ciertas contradicciones no exentas de consecuencias prácticas ${ }^{26}$. En efecto, como es sabido, la existencia de un gobierno cesante se produce, según el artículo 101, por la convocatoria de elecciones generales, la pérdida de la confianza parlamentaria o la dimisión o fallecimiento del presidente del gobierno. Producido alguno de tales eventos, el rey; en el supuesto ordinario ${ }^{27}$, iniciará formalmente el procedimiento, que se traducirá en la apertura de un período de consultas; si la existencia de un gobierno cesante es debido a la celebración de elecciones generales, tales consultas se llevarán a cabo tras la renovación del Congreso, y en los demás supuestos, tras aceptar el rey la dimisión. Sin embargo, el artículo 114.1, al regular la pérdida de una votación de confianza, exige la dimisión del gobierno para que el rey pueda iniciar el procedimiento de nombramiento («procediéndose a continuación», dice el art. 114.1). De esto se puede deducir la paradójica situación de un gobierno en funciones (según el art. 101) que no produce eo ipso la iniciación de un procedimiento de nombramiento de gobierno (art. 114.1), y si bien es cierto que dicha situación no debe prolongarse más que unas horas, no deja de sembrar la duda de si ese gobierno en funciones puede acometer una disolución de las Cámaras, máxime cuando la limitación contenida en el artículo 115.2 se circunscribe a la moción de censura. No obstante, parece que una interpretación sistemática del texto constitucional impone hacer extensiva la limitación contenida en ese último precepto a los casos de pérdida de la votación de confianza. En efecto, es preciso recordar que tanto la teoría constitucional, como el artículo 97 de la Constitución española, encomiendan al gobierno, de un lado, la función gubernamental o de dirección política, y de otro, la dirección de la Administración; pues bien, parece claro que la función política del gobierno marcha vinculada a la confianza parlamentaria y sólo se mantiene en tanto aquélla existe (la llamada por el profesor Sánchez-Agesta «relación de confianza»), en tanto que el gobierno en funciones tiene por objeto evitar la paralización de la Administración; parece lógico, pues, que, roto el vínculo de la confianza del Congreso, el gobierno quede convertido automáticamente

${ }^{26} \mathrm{La}$ regulación constitucional de las crisis de gobierno cuenta con ambigüedades y lagunas que habrá que puntualizar por vía legislativa, interpretación del Tribunal constitucional o usos constitucionales. Así nada se dice de la posición constitucional del gobierno en funciones, o entre las causas que fuerzan la dimisión del gobierno se menciona la celebración de «elecciones generales», expresión ambigua que parece referirse a la renovación del Congreso, del Senado o de ambas Cámaras, cuando en verdad la elección de un nuevo Senado nada afecta a los mecanismos de responsabilidad política del gobierno.

${ }^{27}$ En el supuesto extraordinario de una moción de censura, es el Congreso de los Diputados quien, por principio de estabilidad, sumariza las fases de consultas, propuestas y confianza en el mismo acto en que provoca la crisis del gobierno anterior al aprobar la moción de censura. 
en gestor de la Administración, pero no pueda acometer una disolución de la Cámara, que constituye por excelencia un acto de dirección política. La intervención del rey, aceptando la dimisión, refrenda y formaliza la pérdida de la confianza parlamentaria, a la par que inicia un proceso de nombramiento de nuevo gobierno, pero no es el elemento constitutivo de la crisis.

Producida, pues, la crisis de gobierno, se inicia propiamente, y con las especificaciones citadas, el procedimiento de nombramiento de presidente, iniciativa que corresponde al rey, mediante la celebración de consultas y la propuesta de un candidato, en el supuesto ordinario, y al Congreso, mediante la aprobación de una moción de censura, sintetizando en único acto tres fases (consultas, propuestas y confianza), en el procedimiento extraordinario. Sin embargo, no es la moción de censura constructiva, a pesar de su carácter excepcional, la que plantea problemas de interpretación jurídica como vía de nombramiento del presidente del gobierno ${ }^{28}$, sino que, por el contrario, en la medida en que reduce a sus mínimos elementos dicho procedimiento, ilustra acerca del carácter y contenido de las distintas fases del procedimiento ordinario.

De un lado, la intervención del rey, en las primeras fases del procedimiento ordinario, no puede ser interpretada como una intervención personal y discrecional, sino limitada por el fin a lograr, esto es, encontrar el candidato que arrastre tras de sí la confianza de una mayoría parlamentaria. En efecto, desde el momento en que el Congreso tiene facultad de decisión autónoma para el otorgamiento de confianza al presidente del gobierno, mediante el voto de censura constructivo, la intervención del monarca en el procedimiento ordinario queda limitada a una tarea de mediación entre las fuerzas parlamentarias, posibilitando la consecución de acuerdos entre aquéllas, que es a las que la Constitución asigna poder de decisión; el rey queda entonces configurado como vía de encuentro y no como un partícipe más en la decisión. En consecuencia con ello, las consultas constituyen «verdaderas sesiones de trabajo en busca de una solución» ${ }^{29}$, de cuya complejidad da prueba el hecho de que en algún país se haya llegado a descargar dicha función en la figura del informador ${ }^{30}$. No parece así plenamente acertado, aunque justificado por anteriores experiencias ${ }^{31}$, el carácter restrictivo con que aparecen reguladas las consultas en el art. 99.1, siendo más lógico interpretar dicho precepto con Alzaga, como un techo mínimo, sin perjuicio de que el monarca, en caso necesario, pueda recabar las consultas que estime convenientes a tal fin ${ }^{32}$. De igual modo, la propuesta del candidato, como ha dicho Satrústegui, «no encierra poder discrecional alguno que posibilite o justifique una extralimitación del ámbito simbólico y mode-

${ }^{28}$ Para dicha cuestión, véase J. R. Montero, La moción de censura en la Constitución de 1978, en «Revista de Estudios Políticos», n. 12 (1979), en especial el epígrafe III.

${ }_{29}$ Ruy López, La designación del presidente de gobierno, en Informaciones, 1979.

${ }^{30}$ Así, en Bélgica, véase $\mathrm{B}$. Waleffe, Le roi nomme et révoque ses ministres, Bruselas, 1971 , págs. 28 y sigs.

${ }_{31} \mathrm{Me}$ refiero al excesivo número de consultas celebradas por Alcalá Zamora con motivo de las crisis de gobierno en la II República; véase J. T. Villarroya, La formación de gobierno durante la II República española, en «Revista de Estudios Políticos», n. 204 (1975).

32 O. Alzaga, La Constitución española, Madrid, 1978, pág. 627. 
rador en que ha de desenvolverse la acción del Jefe del Estado ${ }^{33}$, y el refrendo de dicho acto por el presidente del Congreso, así como las transformaciones que sufrió dicha institución en el proceso constituyente, hay que encuadrarlo en dicho ámbito. Con ello no trato de asignar protagonismo al presidente del Congreso en la propuesta, al modo como sucede en Suecia (art. 2. ${ }^{\circ}$ de la Ley Orgánica del Gobierno), sino destacar de nuevo la función de mediación del rey entre las fuerzas parlamentarias, a través de la intervención del coordinador por excelencia de los trabajos parlamentarios: el presidente del Congreso.

Una segunda cuestión del procedimiento ordinario del nombramiento de gobierno que queda esclarecida mediante su comparación con el procedimiento previsto en el artículo 114 es el de la naturaleza de la intervención parlamentaria, concediendo o denegando la confianza al candidato.

Evidentemente, se trata del momento más relevante de todo el proceso, siendo la intervención parlamentaria el elemento constitutivo de la formación de la voluntad estatal en este punto. La Constitución española se inscribe así en el ámbito de los regímenes parlamentarios precedentemente citados, en que la voluntad parlamentaria constituye el elemento previo y esencial de la formación de gobierno, frente a aquellos otros (Bélgica, Francia, Portugal e Italia) en que la intervención parlamentaria se virtualiza a través de un control ex post del acto de nombramiento de gobierno, dato que pone de manifiesto el lugar central del Congreso de los Diputados frente al Jefe del Estado, como órgano arbitral, en la Constitución española.

Ahora bien: ¿qué carácter tiene esa votación parlamentaria, qué elementos la configuran y qué formalidades ha de seguir?

En primer término, la naturaleza de la votación de confianza plantea la cuestión de si tiene el carácter de una elección, en cuanto otorga al elegido por la Cámara de unas facultades constitucionales, o si, por el contrario, existe un ámbito de creación y remodelación del ámbito jurídico, como, por ejemplo, sucede con la función legislativa, pudiendo matizar la intensidad y alcance de la voluntad parlamentaria.

Pues bien, encuadrado así el tema, creo que, a tenor del texto constitucional, se puede optar por el primero de los supuestos, esto es, que se trata de una votación-elección y no de una votación-creación, y ello por dos tipos de razones:

La primera, el ámbito en que se desenvuelve dicha votación, tras una fase previa de consultas y diálogos institucionalizados que culminan con la propuesta del rey. Se trata, en suma, de una alternativa que no se presenta huérfana en su formulación, sino que llega a la Cámara tras un período de gestación, en el que han participado por exigencia constitucional, al menos, todos los representantes de los grupos políticos con representación parlamentaria.

En segundo lugar, por los elementos sobre los que en principio incide la votación de confianza; candidato y su programa. Sin embargo, dada la naturaleza de este último, que veremos a continuación, entiendo que el núcleo esencial y único de la investidura parlamentaria lo constituye la aprobación

${ }^{33}$ M. Satrústegui, ob. cit. 
o rechazo del candidato propuesto. Detengámonos, pues, brevemente en analizar la institución del «programa».

El origen de la figura del programa del gobierno, como en tantas otras instituciones del constitucionalismo moderno, hay que situarlo en la práctica política británica, y el discurso que el soberano pronuncia en la sesión de apertura del Parlamento, cuya autoría corresponde al premier, lo que le convierte en un verdadero programa de gobierno, y junto a dicho solemne antecedente británico hay que mencionar los acuerdos suscritos entre los partidos a fin de fijar los puntos de una posible coalición de gobierno.

No obstante, a nivel teórico, medie coalición gubernamental o se trate de un gobierno homogéneo, parece obvio que el órgano gubernamental ha de contar con un programa, con un orden de prioridades, máxime en sistemas políticos como los actuales, donde, en gran medida, gobernar es programar. El profesor Sánchez Agesta ha dicho al respecto: «El gobierno ha de prever toda una estrategia, como una serie de actos coherentes y coordinados entre sí que permiten conseguir los objetivos. La programación aparece así como un contenido esencial de la función de gobierno» ${ }^{34}$.

Sin embargo, ¿cuál es la naturaleza jurídica de dichos programas y pactos y qué alcance tiene su constitucionalización en relación al proceso de nombramiento de gobierno?

La doctrina alemana, que, como ha puesto de manifiesto Nicolás Muñiz en un reciente trabajo, es la que más se ha ocupado del tema, ha centrado su atención en los programas de gobierno en cuanto encierran un pacto de coalición, en correspondencia a la coyuntura política de la R.F.A. No obstante, los criterios allí sustentados son en gran medida generalizables, y por ello merecen ser recogidos.

Así, una corriente bastante extendida considera los pactos como normas jurídicas vinculantes, bien considerándolos verdadero derecho objetivo en función del nivel de abstracción de su contenido, lo cual parece harto discutible en cuanto supone reconocer una potestad normativa a los partidos de la que hoy por hoy carecen, o bien considerándolos como acto extralegal de creación de Derecho.

Una segunda corriente ha intentado dotar a los pactos y programas de un estatuto jurídico propio, bien recurriendo a las analogías de éstos con los pactos de Derecho internacional, así en Kaufmann, bien aplicando categorías de Derecho mercantil y considerando a los pactos como prácticas concertadas, restrictivas de la competencia en una cierta cartelización de la vida política, en frase de Schule, el principal estudioso del tema.

Finalmente, la tercera corriente, y por otro lado dominante, considera inviable la caracterización jurídica de los pactos. Los pactos dirán, no son alegables ante ninguna instancia jurisdiccional y, en consecuencia, la sanción ha de buscarse en la esfera política del juego interpartidista con la denuncia y ruptura de la coalición como razones últimas ${ }^{35}$.

Ahora bien, con independencia de su naturaleza jurídica, ¿cuál es el alcance de su constitucionalización? Lo más frecuente en los textos constitu-

${ }^{34}$ L. Sánchez Agesta, ob. cit., pág. 219.

${ }_{35} \mathrm{~J}$. Nicolás, El contrato de legislatura (mecanografiado), CEC, Madrid, 1978. 
cionales de los últimos treinta años es abrir la posibilidad para que el gobierno, y más aún su presidente, presente un programa, a fin de recabar el respaldo parlamentario hacia su orientación política, sin que ello implique mayor exigencia que la derivada de la coyuntura política. Así, en Gran Bretaña, entre otros, se ha respetado el ya mencionado tradicional discurso de la $\mathrm{Co}$ rona; en Bélgica se acepta como costumbre constitucional desde 1919 que el recién nombrado primer ministro realice una declaración de política general ante las Cámaras, y en la V República francesa, a través del artículo 49, los gobiernos, hasta 1966, comparecían ante la Asamblea Nacional tras su nombramiento, como ha señalado Claisse. Sin embargo, el caso límite de constitucionalización del programa de gobierno lo representan, además de la vigente Constitución española, la Constitución francesa de 1946, probablemente la primera regulación constitucional explícita de dicha figura, y más aún, el artículo 191 de la Constitución portuguesa, que prescribe los elementos que debe contener el programa, precepto que refrenda el artículo 192, estableciendo que los miembros del gobierno estarán vinculados al programa del gobierno.

Sin embargo, de la validez jurídica de estos programas, aun prescritos a nivel constitucional, no hay más remedio que dudar. La Constitución española hace posible presidentes del gobierno sin programa en su artículo 113 (se entiende sin programa sancionado parlamentariamente), y la puesta en marcha del artículo 99, en marzo del pasado año, viene a confirmar el escaso rigor de aquél ${ }^{36}$. Así, pues, el programa a que se refiere la Constitución española es un acto personalísimo del candidato a presidente del gobierno, una declaración de intenciones, cuyo contenido y valor está supeditado a su posición parlamentaria, pero a la que no se le puede asignar ninguna virtualidad jurídica. En conexión con ello, y parafraseando a Bagehot, el Congreso de los Diputados, mediante la votación de investidura, lleva a cabo primariamente una función de creación de gobierno aceptando o rechazando al candidato propuesto por el rey ${ }^{37}$, pero de la regulación contenida en el artículo 94 no cabe inducir, como sostiene Satrústegui, que, para el Congreso, la investidura suponga además «la adopción de unas orientaciones políticas que han de armonizar y coordinar la acción del ejecutivo y del legislativo», en un cierto paralelismo con lo que la izquierda francesa denomina contrato de legislatura ${ }^{38}$. Por el contrario, la Constitución prevé la investidura como un acto de voluntad parlamentaria, concediendo o denegando la confianza al candidato propuesto. Con ello no pretendo desvalorar la figura del programa de gobierno, sino: situarla en sus justos términos, pues a través de dicha declaración de intenciones el candidato avala su candidatura, pero la votación del Congreso no versa sobre aquélla, que en ningún caso es acto del Parlamento, sino sobre el candidato propuesto por el rey.

De otra parte, la definición de la investidura en los términos precedentes no está exenta de relevancia práctica en el vidrioso tema de la fijación del

${ }^{36}$ Véase sobre dicho tema, en el $\mathrm{n} .{ }^{\circ} 4$ de esta misma revista, la crónica parlamentaria de $M$. Gonzalo.

${ }_{37}$ M. Satrústegui, ob. cit.

${ }^{38}$ Programme Commun de Gouvernement, París, 1973, cap. III, 2, 3. 
orden del día en la sesión de investidura. Como es sabido, el texto constitucional no exige ni prohíbe la celebración de un debate previo a la votación de investidura, lo que se tradujo, con motivo de la investidura de Adolfo Suárez, en una resolución del presidente de la Cámara regulando el procedimiento a seguir, resolución fuertemente criticada principalmente por los grupos parlamentarios socialista y comunista. En realidad, en torno a dicha cuestión práctica se suscitan dos cuestiones de índole distinta: de un lado, el derecho de la Cámara a interpretar e incluso modificar sus propios reglamentos, tema que a todas luces rebasa el presente trabajo ${ }^{39}$; y de otro, la congruencia o no del debate con el procedimiento constitucionalmente previsto para el nombramiento del presidente de gobierno. Pues bien, en relación a este último punto, y dado el carácter de intervención parlamentaria en el procedimiento, según ha quedado expuesto, dicho debate no parece necesario. En efecto, el profesor Pérez Serrano califica el debate como el «momento de la razón» frente a la votación, a la que denomina «momento de la voluntad» ${ }^{40}$, y el Congreso de los Diputados, en el acto de investidura, está expresando un acto de voluntad que no es motivo de transacción ni diálogo. Otra cosa es, como acertadamente señalará J. Santamaría, que en el contexto de las democracias semiplebiscitarias contemporáneas el debate parlamentario (quizá fuera preferible hablar de la intervención de los portavoces de los grupos parlamentarios) cumpla una función básica e inexcusable, la de fijar públicamente, de cara a la opinión, la posición razonada de cada partido sobre el tema que se discute ${ }^{41}$, máxime en el caso de que se trate de gobiernos de coalición, intervenciones que, para mayor realce, se pueden (e incluso conviene) establecer por vía legislativa o reglamentaria tras la presentación de su programa por el candidato, pero que no llegan a tener la naturaleza de un verdadero debate parlamentario.

Finalmente, en relación a la votación de otorgamiento de confianza, es preciso advertir que el tantas veces citado artículo 99 de la Constitución española establece para dicha ocasión dos posibles mayorías: la mayoría absoluta de la Cámara, en una primera votación, y la mayoría simple, en una segunda votación cuarenta y ocho horas después de la anterior. Hace así su aparición una vez más en nuestro texto constitucional la exigencia de mayorías cualificadas, de difícil carcterización jurídica, como ya pusiera de manifiesto en su día C. Schmitt ${ }^{42}$ y que aquí parecen obedecer a exigencias de carácter político, permitiendo a los grupos parlamentarios matizar la intensidad de su aceptación o rechazo del candidato, absteniéndose o ausentándose del salón de sesiones en la segunda votación. El candidato propuesto puede así subsidiariamente obtener la confianza sin un respaldo parlamentario mayoritario, a condición de que no genere una oposición frontal y explícita de la mayoría de la Cámara. El profesor J. Santamaría criticó, en relación al anteproyecto, esta dualidad de mayorías, en especial la exigencia de mayoría

\footnotetext{
${ }^{39}$ Sobre dicho tema, véase O. Alzaga, Contribución al estudio del Derecho parlamentario, en «Revista de Derecho Público», n. ${ }^{\circ} 62$ (1976).

${ }^{40}$ N. Pérez Serrano, Tratado de Derecho politico, Madrid, 1976, pág. 791.

${ }^{41} \mathrm{~J}$. Santamaría, El debate de investidura, en El País, 1979.

42 C. Schmitt, ob. cit., pág. 103.
} 
absoluta en primera votación, por considerarla contradictoria con la moción de censura constructiva, ya que «si para censurar a un gobierno en ejercicio se requiere la mayoría absoluta, debería entenderse que un gobierno cuenta con la confianza del Congreso y puede empezar a existir simplemente si no se le opone la mayoría absoluta» ${ }^{43}$, pero también puede argumentarse en sentido contrario, entendiendo reñido con la lógica que un presidente de gobierno, nombrado por mayoría simple, sólo pueda ser sustituido, si el nuevo candidato obtiene el respaldo de la mayoría absoluta. Ciertamente, la fuente de inspiración en dicho punto de las constituyentes es clara: el artículo 63 de la Ley Fundamental de Bonn, que prevé igualmente dos tipos de mayorías y establece también unos artículos después de la moción de censura constructiva. Sin embargo, creo que lo que especialmente representa dicha regulación es el ser un claro exponente de la especial «autonomía» que el constitucionalismo contemporáneo asigna a la estructura gubernamental, a la que ya hice referencia, y del que la Constitución española de 1978 es una muestra. En efecto, a través de dicha formulación se propicia, en principio, una mayor estabilidad, puesto que es más fácil nombrar un gobierno que derribarlo, y sobre todo se abre la posibilidad a gobiernos apoyados por una mayoría simple, y que no generan una oposición frontal, para que gobiernen con mayorías alternativas $\mathrm{y}$, por tanto, con un elevado margen de autonomía respecto a unas y otras; todo ello sin renunciar al «desideratum» originario de un gobierno comisionado de una mayoría absoluta en el Parlamento. Sin embargo, lo que carece entonces de significado jurídico es la exigencia de mayoría absoluta en primera votación, pues si políticamente parece establecer presidentes de gobierno de dos categorías, desde el plano jurídico la dualidad es irrelevante y tiene un alcance meramente estético.

En todo caso, y obtenida por el candidato la confianza del Congreso, por cualquiera de las dos mayorías, se desarrolla la última fase del procedimiento: el nombramiento por el rey, fase que no parece precisar mayores aclaraciones, pues, dado lo taxativo del enunciado, parece obvio que ha de producirse de modo automático.

\section{C) El nombramiento de ministros}

Culminado así el proceso de nombramiento de presidente de gobierno, se desarrolla aquel otro que le va encadenado, la asignación de las restantes carteras ministeriales. De su brevedad no parece posible dudar: propuesta del presidente del gobierno y nombramiento por el rey. Sin embargo, ¿cabe dotar de algún contenido relevante a la intervención del monarca?

Evidentemente, el peso específico del Jefe del Estado y del primer ministro, en la determinación de los restantes miembros del gobierno, depende de factores tan coyunturales como la personalidad y experiencia política respectiva. La descripción que ha hecho de dicho tema el profesor Villarroya en relación a la II República española es suficientemente elocuente al respecto ${ }^{44}$.

${ }^{43}$ J. Santamaría, Las relaciones entre el gobierno y las Cortes en el Anteproyecto, en Estudios sobre el proyecto de Constitución, Madrid, 1978, pág. 131.

${ }^{44} \mathrm{~J}$. T. Villarroya, ob. cit. 
Sin embargo, a nivel jurídico resulta difícil dotar de un contenido preciso a los términos «propuesta» y «nombramiento», que han motivado amplios debates doctrinales en Italia y Alemania ${ }^{45}$ en torno a si el Jefe del Estado puede llegar a vetar una propuesta del primer ministro en dicho punto.

La doctrina dominante ${ }^{46}$ parece sustentar, con Konrad Hesse, una respuesta negativa, y, en consecuencia, el Jefe del Estado no puede oponerse a las propuestas formuladas por el primer ministro, posición compartida en Italia por Petri, que ve la intervención del Jefe del Estado como una facultad estrictamente formal.

En igual sentido se manifiesta Fausto Cuocolo, aunque, de modo más matizado, advierte de la posibilidad de que dispone el Jefe del Estado de argumentar y dialogar acerca de la oportunidad y justeza de una propuesta ${ }^{47}$.

Pero tampoco han faltado voces en favor de conceder al Jefe del Estado un limitado control material, aunque nunca pueda versar sobre cuestiones de oportunidad y coyuntura política. Así, Mentzel ${ }^{48}$, en un esfuerzo de síntesis, ha considerado tres circunstancias que justificarían, en la R.F.A., un derecho de examen y, en su caso, de veto del presidente federal. En primer término, cuando existan dudas sobre la observancia del orden fundamental democrático y liberal por el ministro propuesto (dado el carácter supraconstitucional que la opinión dominante en la R.F. A. atribuye a dicho principio); en segundo lugar, cuando hayan mediado escándalos de tipo personal, o abusos del cargo desempeñado, o, finalmente, el haber desempeñado actividad política en la época nacional-socialista. A tales causas de un posible derecho de veto, Schneider añade la circunstancia de que el ministro propuesto no goce de respaldo de la mayoría cuando la investidura parlamentaria sólo versa sobre el primer ministro, como, por ejemplo, sucede en España.

Obviamente, los argumentos precedentes son susceptibles de extrapolación y aplicación a la Constitución española, y en concreto, a su artículo 100 . Así, Alzaga ha dicho que «si bien en las Monarquías parlamentarias se ha ido consagrando el principio de que el rey nombra, pero no elige, es evidente que el rey conserva la facultad de ser oído e influir sobre el presidente del gobierno acerca de la oportunidad de no incluir a determinada persona en el gobierno», y Sánchez Agesta, basándose en la información obtenida por el rey durante la fase de consultas para el nombramiento de primer ministro, estima que «el acto del rey nombrando y separando los ministros no implica una respuesta automática de aceptación de la propuesta y que el rey puede hacer observaciones que tienen más peso que el de un puro consejo»; asimismo, Satrústegui afirma que «las sugerencias del Jefe del Estado pueden llegar a desempeñar una influencia no desdeñable en la formación del equipo ministerial», llegando incluso a admitir la posibilidad de que el rey niegue

${ }^{45}$ En Francia, en cambio, parece haber un asentimiento casi general acerca de la importancia de la función presidencial.

${ }^{46}$ Véase K. Von Beyme, ob. cit., págs. 532 y sigs.

${ }^{47} \mathrm{~F}$. Cuocolo, Il governo nel vigente ordinamento italiano, vol. I, en Von Beyme, ob. cit.

${ }^{43}$ E. Mentzel, Ermessensfreibeit des Bundespräsidenten bei der Ernengung der Bundesminister, en Die Oeffentliche Verwaltung, 1965. 
un nombramiento por motivos jurídicos ${ }^{49}$. Evidentemente, y sintetizando, el rey puede formular observaciones y reparos a determinados nombramientos, y ello en base tanto al precitado artículo 100 (toda propuesta precisa ser aceptada), como por la función arbitral que le confiere el artículo 56. Sin embargo, dicha intervención real no puede en ningún caso interpretarse como concesión de un poder jurídico de veto de algún nombramiento, y ello por dos tipos de razones: de un lado, por el taxativo carácter reglado con que aparecen reguladas en la Constitución española las facultades del rey, en función del refrendo, que impide formalizar jurídicamente un posible veto; si, según los artículos 56 y 64, los actos del rey serán refrendados por el presidente del gobierno, careciendo de validez sin dicho refrendo, no existe posibilidad jurídica para el rey de actuar en contra de los criterios del presidente del gobierno. De otro lado, por el contexto general del nuevo orden político, que la Constitución define en su artículo $10^{\circ}$ como Monarquía parlamentaria; en efecto, desde el momento en que el artículo 1.3 proclama como forma política del Estado español la Monarquía parlamentaria se está constitucionalizando un determinado modo de ejercer el rey sus poderes jurídicos, que, si formalmente son los mismos que en la Monarquía constitucional, por mor de aquella declaración quedan supeditados en su efectiva virtualización al órgano refrendante, a excepción de la reserva de poder para situaciones excepcionales, que se constitucionaliza en el artículo 56, cuando dice que el rey «arbitra y modera el funcionamiento regular de las instituciones» ${ }^{50}$. El rey, en suma, podrá, en el nombramiento de ministros, aconsejar, asesorar, con todo el peso de su experiencia política (al igual que en la convocatoria de un referéndum o el decreto de disolución de las Cámaras), consejo y asesoramiento que obviamente habrá que entender avalados con fuertes razones, pero constitucionalmente no podrá oponerse de modo abierto y explícito a las propuestas del presidente del gobierno, pues ni tiene cauces formales para llevarlo a cabo, ni constitucionalmente está habilitado para ello.

\footnotetext{
${ }^{49}$ L. Sánchez Agesta, ob. cit., pág. 240; O. Alzaga, ob. cit., pág. 632; M. Satrústegui, ob. cit.

${ }_{90}$ A nadie se oculta que, con carácter general en todo el presente trabajo y de modo particular en el nombramiento de ministros, se sustenta una interpretación restrictiva del papel del rey a partir de una determinada concepción de la constitucionalización de la fórmula «Monarquía parlamentaria»; el poder de reserva contenido en dicha fórmula y concretado en el art. 56 se entiende sumamente limitado, en especial por el adjetivo «regular» que allí se emplea, que implica, al contrario, una situación de excepcionalidad. Sin embargo, tratándose obviamente de un concepto jurídico indeterminado («funcionamiento regular de las instituciones»), es susceptible de una interpretación más extensiva de las funciones del monarca en todo el proceso; basta interpretar como funcionamiento irregular cualquier escollo en la formación de gobierno.
} 
BIBLIOGRAFIA SELECCIONADA

A) En general

Colliard, J. C.: La désignation du Premier Ministre en régime parlamentaire, en Mélanges Burdeau, París, 1977.

Colliard, J. C.: Les Régimes Parlamentaires Contemporains, París, 1978.

Gaudemet, P.: Le pouvoir exécutif dans les pays occidentaux, París, 1966.

Ramírez, M. (ed.): El control parlamentario del gobierno en las democracias pluralistas, Barcelona, 1978.

Riker, W. H.: The theory of political coalitions, New Haven, 1962.

Swann, A. de: Coalitions theories and Cabinet formations, Amsterdam, 1973.

Von Beyme, K.: Die parlamentarischen Regierungssysteme in Europa, Munich, 1970.

\section{B) Sistemas particulares}

Amphoux, J.: Le chancelier fédéral dans le régime constitutionnel de la R.F.A., París, 1962.

Claisse, A.: Le premier ministre de la V.e République, París, 1972.

Damgaard, E.: The Parliamentary basis of Danish governments: the patterns of coalition formation, en «Scandinavian Political Studies», n. 4 (1969).

Ellwein, T.: Das Regierunssystem der Bundesrepublik Deutscbland, Colonia, 1973.

Fabre, M. H.: Un écbec constitutionnel: l'investiture du président du Conseil des ministres, en «Revue du Droit Public», n.。 1 (1951).

Galizia, M.: Studi sui rapporti fra Parlamento e Governo, Milán, 1972.

Gehrig, N.: Parlament-Regierung-Opposition. Dualismus als Voraussetzung fïr eine parlamentarische Kontrolle der Regierung, Munich, 1969.

Hennis, W.: Richtlinienkompetenz und Regierungstecbnik, Tubinga, 1964.

Jennings, I.: Cabinet government, Cambridge, 1961.

Junker, E. U.: Die Richtlinienkompetenz des Bundeskanzlers, Tubinga, 1965.

King, A. (ed.): The British Prime Minister, Londres, 1969.

Loewenstein, K.: L'investiture du Premier Ministre en Angleterre, en «Revue du Droit Public», n. 6 (1966).

Menzel, E.: Ermessensfreibeit des Bundespräsidenten bei der Ernengung der Bundesminister, en Die Oeffentliche Verwaltung, 1965.

Moodie, G. C.: The monarch and the selection of a Primer Minister, en «Political Studies», n. 1 (1957).

Pfister, W. E.: Regierungsprogramm und Richtlinien der Politik, Berna, 1974.

Rizza, G.: Il Presidente del Consiglio dei Ministri, Nápoles, 1970.

Romano, A. A.: La formazione del Governo, Padova, 1977.

Schneider, H.: Die Regierungsbildung nach dem Bonner Grundgesetz, en Neue Juristiscbe Wochenschrift, 1953.

Villarroya, J. T.: La formación de gobierno durante la II República, en «Revista de Estudios Políticos», n. ${ }^{\circ} 204$ (1975).

Waleffe, B.: Le roi nomme et révoque ses ministres, Bruselas, 1971.

Welan M.: Der Bundeskanzler im österreichischen Verfassungsgetüge, Wien, 1971.

\section{C) Constitución española}

Aja, E.: La supremacía de las Cortes. ¿Quién ba de dirigir el Estado: el gobierno o las Cortes?, en La izquierda y la Constitución, Barcelona, 1978.

Alzaga, O.: La Constitución española de 1978, Madrid, 1978.

Calvo, M. A.: La relación entre el gobierno y las Cortes, en Lecturas sobre la Constitución española, vol. I, Madrid, 1978. 
Fernández Miranda, F.: El gobierno en la nueva Constitución, en Lecturas sobre la Constitución española, vol. II, Madrid, 1978.

Montero, J. R.: La moción de censura en la Constitución de 1978: supuestos constituyentes $y$ consecuencias políticas, en «Revista de Estudios Políticos», n. 12 (1979).

Ruy López: La designación del presidente del gobierno, en Informaciones, 20 de enero de 1979.

Sánchez Agesta, L.: El sistema politico de la Constitución española de 1978, Madrid, 1980.

Santamaría, J.: Las relaciones entre el gobierno y las Cortes en el Anteproyecto, en Estudios sobre el Proyecto de Constitución, Madrid, 1978.

Santamaría, J.: El debate de investidura, en El País, 24 de marzo de 1979.

Satrústegui, M.: Ante la formación del próximo gobierno, en El París, 9 y 10 de marzo de 1979 . 